\title{
Research on the Measurement of Logistics Industry Agglomeration
}

\author{
Yanhui Han \\ School of Traffic and Transportation \\ Beijing Jiaotong University \\ Beijing 100044, China \\ e-mail: yhhan@bjtu.edu.cn
}

\author{
Qinglun Zhong \\ School of Traffic and Transportation \\ Beijing Jiaotong University \\ Beijing 100044, China \\ e-mail: 09252060@bjtu.edu.cn
}

\begin{abstract}
Logistics had become an important source of growth in China. Some part of this rapid logistics industrial development could be attributed to the industrial agglomeration in the country. Understanding logistics industry agglomeration and its driving forces is critical for the formulation of logistics industrial policy in China. Crucial to this process is the measurement of agglomeration. The paper used location quotient to analyze logistics industry agglomeration of the 31 provinces in China, and then contrasted with other industries. There are greater differences of agglomerate economies among different industries. High location quotient competencies are generally found in high location quotient industries that are vital for the region's continued economic stability and growth.
\end{abstract}

Keywords-location quotient; industry agglomeration; logistics industry

\section{INTRODUCTION}

Many industries are geographically concentrated. Industrial agglomeration has been considered a source of sustainable competitive advantage for a national or regional economy. Industrial agglomeration stresses in industry's regional distribution, describes some industrial spatial distribution condition. Modern logistics industry is a kind of new composite services industry which transportation, warehousing, distribution processing, logistics, packaging, transportation loading and unloading, distribution and regional distribution industries etc. in the process of logistics are combined together to form a complete supply chain through the use of modern information technology and management means. Logistics industrial agglomeration is geographical agglomeration of logistics activities and it is an important process for promoting industrial and economic development. They are characterized, among other factors, by low transportation costs and high transportation service level when moving items in and out of the cluster. As such, far from being isolated, logistics clusters are the building blocks of globalization. Freight moves along international and national trade lanes, from cluster to clusters, and such movements enable the efficient flow of goods worldwide. As the global flow increase and the flow through these logistics clusters increase, they become, even more efficient, attracting even more economic activities and freight flows [1].

The phenomenon of industrial agglomeration has drawn great interests from both researchers and policy makers during the last few decades. In the academic field, voluminous theoretical and empirical studies on industrial agglomeration have been undertaken. Marshall (1920) emphasized three different types of transport costs-the costs of moving goods, people, and ideas-that could be reduced by industrial agglomeration. Porter (1990) has promoted the importance of industrial "clusters" in generating competitive advantage for firms and regions. Chatterjee (2003) considered that agglomeration economies derive benefits from the location of activities near a specific facility, provide powerful forces and explain the advantages of the clustering of services around a particular facility. Klosterman (1993) presents the basic formula for a location quotient in regional science. O'Donoghue and Gleave (2004) proposed standardized location quotient. Cheng Dazhong and Huangwen (2005) analyzed the location and regional specialization of service industry in China using location quotient [2]. Li Pei (2007) analyzed the essential factor and the development of logistics agglomeration, used location quotient to measure the concentration degree of logistics agglomeration in Shanghai [3]. Zhong Zuchang (2012) used location quotient to analyze logistics industry agglomeration of the 31 provinces in China, and then incorporates the regional spatial correlation factors into the logistics industry agglomeration analysis model. The results show that there is spatial correlation and positive spatial spillover effects between 31 provinces logistics industry [12]. Overall, domestic and foreign scholars did extensive research on the industrial agglomeration.

\section{MEASUREMENT OF LOGISTICS INDUSTRY AGGLOMERATION}

Commonly used measurements of industry agglomeration are Concentration Ratio, Concentration Index of Industrial Space, Spatial GINI Coefficient, Hannah-Kay Concentration Indices, Herfindahl-Hirschman Index, and Entropy Index etc. The Location Quotient Technique is the most commonly utilized analysis method for logistics industry agglomeration. It was developed in part to offer a 
slightly more complex model to the variety of analytical tools available to economic base analysts. Location quotient is basically a way of quantifying how concentrated a particular industry, cluster, occupation, or demographic group is in a region as compared to the nation. It can reveal what makes a particular region "unique" in comparison to the national average. The location quotient technique is based upon a calculated ratio between the local economy and the economy of some reference unit. This ratio, called an industry "location quotient" gives this technique its name [5].

The basic uses of industry location quotient include these: to determine which industries make the regional economy unique; to identify the "export orientation" of an industry and identify the most export-oriented industries in the region; to identify emerging export industries beginning to bring money into the region.

To calculate location quotient the following formula is applied.

$$
L Q_{i}=\left(e_{i} / e\right) /\left(E_{i} / E\right)
$$

Where,

$L Q_{i}$ represents location quotient of industry in regional $i, e_{i}$ is employment (output) of industry in region $i, e$ is total employment (output) of industry in all regions. $E_{i}$ is total employment (output) of all industries in region $i$, and $E$ is total employment (output) of the overall economy.

When $L Q_{i}=1$ that means the employment (output) is equal for the national and regional economy. Therefore the industry is non-basic and supply is just equal to demand.

If $L Q_{i}<1$, the employment (output) is not sufficient to meet the local demand and imports are needed. It is also nonbasic.

If $L Q_{i}>1$ the employment (output) is more than sufficient to meet the local demand and exporting the surplus is an option. It is basic.

\section{EMPIRICAL STUDY}

Transport, storage and post have always been an important part of logistics. The paper uses the value of regional output and employment of transport, storage and post to compute agglomeration for logistics industries. Simultaneity, the paper selects 31 provincial level administrative units of China as the regional units. Data are available from the China Statistical Yearbook from 2004 to 2012 [4].

\section{A. Logistics Industry Location Quotient}

The following study uses the above formula. Location quotients in terms of employment in China from 2003 to 2011 are shown in Table I. Location quotients in terms of the value of output are shown in Table II.

As shown in Table I and Table II, growing employment and the value of output paired with ascending location quotient indicates that the logistics industry is growing as fast in the region as it is in the national economy. Although there are some provinces that are highly agglomerated in terms of employment, for the value of output are distinct. This finding provides further support for the idea that different processes generate agglomeration at different levels of geography.

From employment perspective, sort into descending order is Liaoning, Guangdong, Shandong, Beijing, Jiangsu, Shanghai, Zhejiang etc. From the value of output perspective, to sort in descending order is Shandong, Jiangsu, Guangdong, Hebei, Zhejiang, Liaoning, Inner Mongolia etc. This sort is not consistent with the order of location quotients. In fact, location quotient is only from regions specialized in an industry, which represents the position of logistics industry in the national economy. From Table we can obviously find out that 7 of 31 provincial logistics industry have $L Q_{i}>1$ both from employment and output perspective, such as Liaoning, Beijing, Hebei, Guangxi, Tianjin, Shanxi and Inner Mongolia. It indicates that location quotients are higher than national average and logistics industrial clusters are formed. The main cause is that these provinces are emphasis on the development of modern logistics industry. Since 2009 March the state promulgated the "logistics industry restructuring and revitalization plan", the provinces introduce some related policy to promote the modern logistics industry to develop rapidly. Contrary, there are 11 of 31 provincial logistics industry have $L Q_{i}<1$, such as Chongqing, Shaanxi, Jiangxi, Jiangsu, Tibet, Guangdong, Anhui, Zhejiang, Henan, Sichuan and Yunnan. Logistics industries are not yet as concentrated in the region as they are at the national level. Although the employment and the value of output of Guangdong, Shandong, Jiangsu, Zhejiang, Shanghai is higher, but takes up a smaller proportion of national economy, which fully demonstrates the limitations of location quotient method. The method does not consider the different level of regional economy.

TABLE I. LOCATION QUOTIENT IN THE TERMS OF EMPLOYMENT

\begin{tabular}{|c|c|c|c|c|c|c|c|c|c|}
\hline & $\mathbf{2 0 0 3}$ & $\mathbf{2 0 0 4}$ & $\mathbf{2 0 0 5}$ & $\mathbf{2 0 0 6}$ & $\mathbf{2 0 0 7}$ & $\mathbf{2 0 0 8}$ & $\mathbf{2 0 0 9}$ & $\mathbf{2 0 1 0}$ & $\mathbf{2 0 1 1}$ \\
\hline Beijing & 0.828 & 0.992 & 1.118 & 1.256 & 1.370 & 1.403 & 1.400 & 1.482 & 1.630 \\
\hline Tianjin & 1.117 & 1.179 & 1.155 & 1.201 & 1.199 & 1.294 & 1.292 & 1.412 & 1.149 \\
\hline Hebei & 1.038 & 1.133 & 1.140 & 1.092 & 1.057 & 1.088 & 0.874 & 1.064 & 1.027 \\
\hline Shanxi & 1.042 & 1.060 & 1.049 & 1.099 & 1.037 & 1.013 & 0.980 & 1.012 & 1.063 \\
\hline $\begin{array}{c}\text { Inner } \\
\text { Mongolia }\end{array}$ & 1.329 & 1.305 & 1.355 & 1.329 & 1.414 & 1.481 & 1.484 & 1.524 & 1.467 \\
\hline Liaoning & 1.581 & 1.652 & 1.769 & 1.745 & 2.051 & 2.025 & 2.397 & 2.077 & 2.101 \\
\hline Jilin & 1.547 & 1.399 & 1.370 & 1.527 & 1.528 & 1.480 & 1.337 & 1.227 & 1.253 \\
\hline Heilongjiang & 1.318 & 1.327 & 1.323 & 1.365 & 1.389 & 1.333 & 1.316 & 1.246 & 1.367 \\
\hline Shanghai & 1.142 & 1.134 & 1.188 & 1.251 & 1.276 & 1.411 & 1.406 & 1.528 & 1.536 \\
\hline Jiangsu & 0.759 & 0.721 & 0.678 & 0.669 & 0.638 & 0.653 & 0.638 & 0.668 & 0.672 \\
\hline Zhejiang & 0.706 & 0.672 & 0.675 & 0.636 & 0.576 & 0.582 & 0.562 & 0.586 & 0.603 \\
\hline Anhui & 1.100 & 1.113 & 1.138 & 1.120 & 1.085 & 1.005 & 0.796 & 0.718 & 0.748 \\
\hline Fujian & 0.621 & 0.651 & 0.638 & 0.632 & 0.591 & 0.619 & 0.593 & 0.648 & 0.642 \\
\hline Jiangxi & 1.062 & 1.030 & 1.089 & 1.089 & 1.069 & 1.090 & 1.044 & 1.014 & 0.973 \\
\hline Shandong & 0.725 & 0.732 & 0.702 & 0.726 & 0.764 & 0.785 & 0.832 & 0.894 & 0.946 \\
\hline Henan & 1.062 & 1.096 & 1.081 & 1.025 & 1.017 & 0.918 & 0.804 & 0.799 & 0.778 \\
\hline
\end{tabular}




\begin{tabular}{|c|c|c|c|c|c|c|c|c|c|}
\hline Hubei & 1.266 & 1.206 & 1.202 & 1.165 & 1.262 & 1.241 & 1.174 & 1.112 & 1.070 \\
\hline Hunan & 1.111 & 0.987 & 0.962 & 0.977 & 0.958 & 0.897 & 0.850 & 0.921 & 0.833 \\
\hline Guangdong & 0.722 & 0.708 & 0.700 & 0.763 & 0.731 & 0.759 & 0.762 & 0.829 & 0.880 \\
\hline Guangxi & 1.288 & 1.296 & 1.361 & 1.438 & 1.429 & 1.415 & 1.436 & 1.358 & 1.348 \\
\hline Hainan & 1.093 & 1.185 & 1.244 & 1.213 & 1.063 & 1.323 & 1.306 & 1.383 & 1.350 \\
\hline Chongqing & 1.015 & 1.062 & 1.054 & 1.126 & 1.046 & 1.036 & 0.966 & 1.024 & 0.906 \\
\hline Sichuan & 0.843 & 0.868 & 0.905 & 0.869 & 0.904 & 0.865 & 0.882 & 0.947 & 0.874 \\
\hline Guizhou & 0.913 & 0.891 & 0.905 & 0.884 & 0.894 & 0.962 & 0.955 & 1.047 & 0.941 \\
\hline Yunnan & 1.007 & 0.944 & 1.008 & 0.889 & 0.779 & 0.798 & 0.779 & 0.792 & 0.780 \\
\hline Tibet & 0.898 & 0.827 & 0.843 & 0.826 & 0.816 & 0.735 & 0.630 & 0.651 & 0.619 \\
\hline Shaanxi & 1.010 & 1.009 & 0.950 & 0.912 & 0.952 & 0.913 & 1.644 & 1.021 & 0.945 \\
\hline Gansu & 0.957 & 0.972 & 0.996 & 0.980 & 0.897 & 0.912 & 0.904 & 0.915 & 0.930 \\
\hline Qinghai & 1.055 & 1.228 & 1.056 & 1.220 & 1.210 & 1.195 & 1.168 & 1.147 & 1.070 \\
\hline Ningxia & 0.941 & 0.911 & 0.891 & 0.804 & 0.716 & 0.859 & 0.830 & 0.860 & 0.887 \\
\hline Xinjiang & 0.968 & 1.049 & 1.102 & 1.089 & 1.074 & 1.086 & 0.984 & 1.068 & 1.114 \\
\hline
\end{tabular}

TABLE II. LOCATION QUOTIENT IN THE TERMS OF THE VALUE OF OUTPUT

\begin{tabular}{|c|c|c|c|c|c|c|c|c|c|}
\hline & & & & & & & & & \\
\hline & & & & & & & & & \\
\hline & & & & & & & & & \\
\hline & & & & & & & & & \\
\hline & & & & & & & & & \\
\hline & 336 & 1. & $\mid 1.641$ & 1 & 1.544 & 1.574 & 1. & 1. & $\mid 1.52$ \\
\hline Lia & & & & & & & & 1.0 & 08 \\
\hline & & & & & & & & & \\
\hline ong & & & & & & & & & \\
\hline & & & & & & & & & \\
\hline & & & & & & & & & \\
\hline & & & & & & & & & \\
\hline & & & & 1 & & & & & 31 \\
\hline & & & & 45 & & & & 1.2 & 5 \\
\hline & & & & & & & & & 1 \\
\hline & & & & & & & & & \\
\hline & & & & & & & & & \\
\hline & & & & & & & & & \\
\hline & & & & & & & & & $\pi$ \\
\hline & & & & & & & & & \\
\hline & & & & & & & & & \\
\hline & & & & & & & & & \\
\hline & & & & & & & & & \\
\hline & 0.9 & & & & & & & & 63 \\
\hline & & & & & & & & 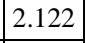 & 17 \\
\hline & & & & & & & & & \\
\hline & & & & & & & & & \\
\hline & & & & & & & 29 & 953 & \\
\hline & & & & & & & 52 & & 17 \\
\hline & & & & & & & & 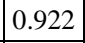 & 8 \\
\hline & & & & & & & & $\mid \begin{array}{l}1.7 . \\
\end{array}$ & \\
\hline & & & & & & & & & \\
\hline
\end{tabular}

\section{B. Compare to Other Industries}

In absence of data on employment for other industry in some province, the value of output for each industry in each province is used to compare with logistics industry. It is shown in Table III.

Table III lists the level of agglomeration at the province levels for 8 industries. These location quotients reveal competencies in which regions are outperforming or lagging behind the nation, as well as which competencies regional economy depends on. High location quotient competencies are also generally found in high location quotient industries that are vital for the region's continued economic stability and growth. Such industries are generally the region's export-oriented industries, which form its economic base. Two-thirds of location quotient of primary industry, industry and construction is greater than 1 , it is more concentrated in the region than average, and also is becoming more concentrated over time. One-thirds of location quotient of wholesale and retail trades, financial intermediation and real estate is greater than 1 .

TABLE III. LOCATION QUOTIENT IN THE TERMS OF OUTPUT OF INDUSTRIES

\begin{tabular}{|c|c|c|c|c|c|c|c|}
\hline & $\begin{array}{l}\text { Primary } \\
\text { industry }\end{array}$ & $\underset{y}{\text { Industr }}$ & $\begin{array}{c}\text { Constru } \\
\text { ction }\end{array}$ & $\begin{array}{c}\text { Wholes } \\
\text { ale and } \\
\text { retail } \\
\text { trades }\end{array}$ & \begin{tabular}{|c|} 
Hotels \\
and \\
Caterin \\
$\mathrm{g}$ \\
Services
\end{tabular} & $\begin{array}{c}\text { Financia } \\
1 \\
\text { intermed } \\
\text { iation }\end{array}$ & $\begin{array}{c}\text { Real } \\
\text { estate }\end{array}$ \\
\hline Beijing & 92 & 0.422 & 0.707 & 412 & 1.018 & 2.744 & 1.554 \\
\hline Tianjin & 155 & 1.080 & 0.718 & 389 & 0.817 & 1.347 & 0.855 \\
\hline Hebei & 303 & 1.080 & 0.903 & .779 & 0.656 & 0.613 & 0.880 \\
\hline Shanxi & 627 & 193 & 0.981 & & 1.104 & 0.930 & 0.470 \\
\hline $\begin{array}{c}\text { Inner } \\
\text { Mongolia }\end{array}$ & 1.000 & 1. & 1.064 & 90 & 1.262 & 0.627 & 0.62 \\
\hline Liaoning & 0.947 & 1.082 & 1.069 & 0.946 & 0.932 & 0.684 & 0.926 \\
\hline Jilin & 28 & 1.046 & 1.071 & & 24 & 96 & 0.530 \\
\hline Heilongjiang & 1.486 & 1.001 & 0.944 & 904 & 1.041 & 561 & 0.869 \\
\hline Shanghai & 0.072 & 0.844 & 0.612 & 1.699 & 0.691 & 388 & 1.248 \\
\hline Jiangsu & 0.686 & 1.020 & 0.972 & 1.167 & 0.889 & 1.066 & 1.315 \\
\hline Zhejiang & 0.538 & 1.022 & 0.946 & 1.091 & 0.911 & 1.701 & 1.219 \\
\hline Anhui & 1.448 & 1.038 & 1.331 & 0.737 & 0.784 & 0.663 & 0.975 \\
\hline Fuji & 09 & 0.983 & 96 & & 0.812 & 89 & 1.219 \\
\hline Jian & 06 & 1.040 & 65 & & 1.097 & .615 & 0.808 \\
\hline Shanc & 63 & 1.055 & 0.987 & 77 & 0.923 & .728 & 0.952 \\
\hline Henan & 33 & 1.165 & 0.896 & 632 & 1.407 & 0.649 & 0.861 \\
\hline Hubei & 38 & 0.978 & 1.063 & 27 & 1.080 & 0.692 & 0.760 \\
\hline Hunan & 547 & 0.929 & 1.029 & & 0.982 & 0.513 & 0.619 \\
\hline Guangd & 50 & 1.042 & 0.552 & & 1.064 & 103 & 1.466 \\
\hline & & & & & 47 & & 0.933 \\
\hline Hainan & 72 & 0.423 & 1.550 & 1.097 & 1.689 & 0.840 & 1.944 \\
\hline Chongqing & 0.927 & 1.054 & 1.390 & 0.801 & 0.789 & 1.417 & 0.930 \\
\hline Sichuan & 1.559 & 1.015 & 1.194 & 0.605 & 1.271 & 0.831 & 0.693 \\
\hline Guizhou & 1.400 & 0.721 & 1.045 & 0.844 & 1.869 & 1.050 & 0.661 \\
\hline Yunnan & 44 & 0.757 & 1.443 & & 1.485 & 1.033 & 0.587 \\
\hline Tibet & & 0.179 & 4.328 & 0.606 & 1.391 & 1.053 & 0.676 \\
\hline Shaanxi & 072 & 1.053 & 1.406 & .888 & 1.013 & 0.695 & 0.747 \\
\hline Gansu & 1.486 & 0.862 & 1.476 & 0.752 & 1.169 & 0.582 & 0.628 \\
\hline Qinghai & 1.020 & 1.093 & 1.597 & 0.602 & 0.538 & 0.754 & 0.409 \\
\hline Ning $x$ & 0.963 & 0.874 & 1.859 & 0.561 & 0.839 & 1.285 & 0.883 \\
\hline Xinjiang & 1.894 & 0.919 & 1.298 & 0.604 & 0.559 & 0.879 & 0.626 \\
\hline
\end{tabular}

This table has a number of interesting implications. First, some of the most agglomerated industries may well be agglomerated because of natural advantage rather than 
because of a spatial externality. Primary industry is an example of this. Second, many of the agglomerated industries are the kinds of industries where one might expect agglomeration economies to be important. Industry, construction, logistics are examples of this. Third, although there are some industries that are highly agglomerated at more than one level of geography, for the most part the lists are distinct. It is important to note here that location quotients can vary significantly depending on the level of industry aggregation. For example, Beijing and Shanghai have a location quotient less than 1.0 for the industry, but, a particular business, such as wholesale and retail trades, financial intermediation and real estate definitely is a local strength.

From the industry perspective, the level of logistics industry agglomeration of Guizhou, Hebei, Inner Mongolia, Shanxi, Shandong, Ningxia and Liaoning is relatively high. Logistics industry has become the leading industry in these regions and gains a strong competitive advantage in its industry. But some regions need to attract more businesses in logistics industries in order to maintain an economy that is sufficiently balanced and diversified in comparison to the national economy.

\section{CONCLUSION}

The formation and strengthening of industrial bases are one of the conditions for developing countries to achieve economic development. The paper confirmed there are significant agglomerate economies in Chinese logistics industry using the provincial data from 2003 to 2011, and there are greater differences of agglomerate economies among different industries. It has been recognized that natural advantages can influence an industry's spatial concentration. The high location quotient for logistics industry in some regions suggests that it is an important source of local economy. A logistics cluster consists of a group of local industries that are closely linked by local supply networks, local customer networks, common labor markets, and access to technical expertise. Logistics clusters present opportunities for balanced movements in and out of cluster efficient and increased the level of service. Focusing on logistics industry clusters in which region enjoys a competitive advantage can help the region understand the strengths and challenges of the local economy and better focus on factors that may foster continued growth for the region.

\section{ACKNOWLEDGMENT}

This research has been supported by "the Fundamental Research Funds for the Central Universities" (2011JBM246)

\section{REFERENCES}

[1] Yossi Sheffi, Logistics Clusters: Delivering Value and Driving Growth, MIT Press, Cambridge, Massachusetts, 2012

[2] CHENG Dazhong, HUANG Wen, "The Location and Regional Specialization of Service Industry in China," Finance \& Trade Economics, Vol.7, 2005, pp. 73-81

[3] LI Pei, WANG Guang-yong, "Positive Analysis of Shanghai Logistics Agglomeration,” Logistics Sci-Tech, Vol.30, 2007, pp. 7273

[4] National Bureau of Statistics of the People's Republic of China, 2012 China Statistical Yearbook, China Statistics Press, Beijing, 2012

[5] Isserman, Andrew M, "The Location Quotient Approach for Estimating Regional Economic Impacts," Journal of the American Institute of Planners, Vol.43, 1977, pp.33-41

[6] Curry, B. and K. D. George, "Industrial concentration: A survey. Journal of Industry Economy”, Vol. 31, 1983, pp.203-55

[7] Rutner SM and Langley CJ, "Logistics Value: Definition, Process and Measurement," International Journal of Logistics Management, Vol.11, 2000, pp.73-82

[8] Meidute I, "Comparative Analysis of the Definitions of Logistics Centres," Transport, Vol.20, 2005, pp.106-110

[9] Deichmann, U., Kaiser, K., Lall, S., and Shalizi, Z., "Agglomeration, Transport, and Regional Development in Indonesia," World Bank Policy Research Working Paper, 2005.

[10] Kuchiki, A., and M. Tsuji, "Industrial Clusters in Asia: Analyses of their Competition and Cooperation," Palgrave Macmillan, 2005

[11] Van der Berg L, Braun E y Van Winden W, "Growth clusters in European cities: an integral approach," Urban Studies, Vol.38, 2001, pp.186-206

[12] Zhong Zuchang, "Research on Logistics Industry Agglomeration and its Determinants Based on Spatial Economics--Empirical Evidence from 31 Chinese Provinces," Journal of Shanxi Finance and Economics University, Vol. 11, 2012, pp. 55-62

[13] Li Yang, "The Empirical Analysis on Western Industrial Agglomeration Level Measurement," Nankai Economic Studies, Vol.4, 2009, pp.144-151. 